\title{
PENGARUH MODEL PEMBELAJARAN NUMBERED HEAD TOGETHER (NHT) TERHADAP HASIL BELAJAR SISWA MUATAN PEMBELAJARAN PPKn KELAS IV DI SDN 221/II TALANG PAMESUN
}

\author{
Isti Wulandari ${ }^{1)}$ \\ Ana Novitasari, M.Pd ${ }^{2}$ \\ Deded Pratama, M.Pd ${ }^{3)}$ \\ 1) Fakultas Keguruan dan Ilmu Pendidikan / Universitas Dharmas Indonesia \\ Istiwulandari436@gmail.com
}

\begin{abstract}
ABSTRAK: Berdasarkan latar belakang peneliti, banyak sekali ditemukannya siswa yang pasif saat proses pembelajaran, interaksi antar siswa yang kurang saat belajar, jarang adanya diskusi kelompok saat belajar, siswa kurang bertanggung jawab mengerjakan tugasnya, dan rendahnya hasil belajar siswa PPKn di kelas IV. Upaya mengatasi permasalah tersebut, diperlukan model pembelajaran yang inovatif dan menarik yaitu Model Pembelajaran Numbered Head Together (NHT). Penelitian ini bertujuan untuk membuktikan pengaruh model pembelajaran Numbered Head Together (NHT) terhadap hasil belajar siswa muatan pembelajaran PPKn kelas IV di SDN 221/II Talang Pamesun. Jenis penelitian ini adalah kuantitatif yang menggunakan metode penelitiannya yaitu Ekperimen. Desain penelitian yang digunakan adalah Pre-Experimental Design dengan bentuk One group pretest posttest design. Sampel yang digunakan adalah seluruh siswa kelas IV di SDN 221/II Talang Pamesun. Hasil penelitian eksperimen ini datanya diolah dengan uji normalitas dan uji hipotesis. Hasil dari uji normalitas yaitu data pretest yaitu $0,550>0,05$ dan signifikansi yang diperoleh dari data posttest yaitu $0,264>0,05$. Artinya data pretest dan posttest siswa kelas IV SDN 221/II Talang Pamesun adalah berdistribusi normal. Sedangkan hasil uji hipotesis yaitu $0,000<0,05$ artinya $\mathrm{H}_{0}$ ditolak dan $\mathrm{H}_{\mathrm{a}}$ diterima. Maka dapat disimpulkan bahwa terdapat pengaruh model pembelajaran Numbered head Together (NHT) terhadap hasil belajar siswa muatan pembelajaran PPKn kelas IV di SDN 221/II Talang Pamesun.
\end{abstract}

Kata kunci: Pengaruh, Model pembelajaran, Model Pembelajaran NHT

\begin{abstract}
Based on the background of the researcher, there are many student who are passive during the learning process, lack of interaction between students when studying, and no group discussion during the learning process. In order to overcome these problems, an innovative and interesting learning model is needed, namely the Numbered Head Together (NHT). This study aims to prove the effect of the Numbered Head Together (NHT) on student learning outcomes civis class IV in SDN 221/II Talang Pamesun. This type of research is quantitative using the method. The research design used is pre-experimental design used in the form of one group pretest posttest design. His sample will be all fourth grade student at SDN 221/II Talang Pamesun. The results of this experimental research date were tested by normality test and hypothesis testing. The result of normality test were pretest data, namely 0,550>0,05 and the significance obtained from the posttest data was 0,264>0,05. Data is normality distributed. Meanwhile the results of the hypothesis is $0,000<0,05$ meaning $H_{0}$ is rejected and $H_{a}$ is accepted. It can be concluded that there is an effect of the numbered head together (NHT) learning model student learning outcome in class IV civics learning content at SDN 221/II Talang Pamesun.
\end{abstract}

Keywords: Effect, learning model, NHT learning model 


\section{PENDAHULUAN}

Undang-Undang Republik Indonesia Nomor 20 Tahun 2003 Tentang Sistem Pendidikan Nasional menyatakan bahwa Pendidikan adalah usaha sadar dan terencana untuk mewujudkan suasana belajar dan proses pembelajaran agar peserta didik secara aktif mengembangkan potensi dirinya untuk memiliki kekuatan spiritual keagamaan, pengendalian diri, kepribadian, kecerdasan, akhlak mulia, serta keterampilan yang diperlukan dirinya, masyarakat, bangsa dan negara. Adapun fungsi dari pendidikan nasional adalah mengembangkan kemampuan dan membentuk watak serta peradaban bangsa yang bermartabat dalam rangka mencerdaskan kehidupan bangsa, bertujuan untuk berkembangnya potensi peserta didik agar menjadi manusia yang beriman dan bertakwa kepada Tuhan Yang Maha Esa, berakhlak mulia, sehat, berilmu, cakap, kreatif, mandiri, dan menjadi warga negara yang demokratis serta bertanggung jawab.

Berdasarkan uraian diatas perlu terjadinya proses pembelajaran yang bermakna di kelas. Pembelajaran merupakan hasil dari ingatan pengetahuan dan pemahaman yang dilakukan siswa dalam memproses informasi pada dirinya sendiri (Huda, 2017). Pada saat belajar siswa akan mengingat atau menyerap apapun pengetahuan atau keterampilan yang didapat, cepat atau lambatnya penerimaan pengetahuan siswa tergantung dengan pengajaran yang diterapkan oleh guru. Supaya pengajaran dapat berjalan dengan efektif, pembelajaran yang semestinya bukan hanya bersifat siswa menerima saja, namun siswa seharusnya aktif terlibat dalam proses pembelajaran yang ditunjukkan oleh guru yang mengarah pada lingkungan kelas yang nyaman dan aman (Huda, 2017).

Proses pembelajaran yang tepat telah diatur dalam Peraturan Pemerintah Nomor 32 Tahun 2013 tentang perubahan PP Nomor 19 Tahun 2015 tentang Standar Pendidikan Nasional yaitu pada standar proses. Dalam standar proses dijelaskan bahwa proses pembelajaran diselenggarakan secara interaktif, inspiratif, menyenangkan, menantang, memotivasi siswa untuk berpartisipasi aktif serta memberikan ruang yang cukup bagi prakarsa, kreatifitas, kemandirian, sesuai dengan pengembangan bakat, minat dan fisik serta psikologis siswa. Langkah pembelajaran pada standar proses dimulai pada penyusunan silabus, RPP, pelaksanaan proses pembelajaran, serta penilaian proses pembelajaran.

Proses pembelajaran dapat tercapai sesuai dengan keinginan diperlukan model yang bervariasi dan menarik sesuai dengan kurikulum 2013. Model pembelajaran merupakan perencanaan atau pola yang digunakan oleh guru sebagai pedoman perencaan pembelajaran di kelas. Salah satu model yang inovatif dan menarik yaitu Model pembelajaran Numbered Head Together merupakan model kooperatif yang setiap siswanya diberikan penomoran yang berbeda-beda dan diberikan kesempatan Model pembelajaran ini dapat meningkatkan keaktifan siswa, meningkatkan 
keterampilan berbicara siswa dengan menjawab pertanyaan, terjadinya interaksi antar siswa dengan adanya diskusi kelompok, serta meningkatkan rasa ingin tahu siswa yang dapat mempengaruhi hasil belajarnya. Pada penelitian yang dilakukan oleh Sri Ayu Rahma Yuni tahun 2018 model pembelajaran ini cocok digunakan pada muatan pembelajaran PPKn, karena dapat memberikan pengaruh yang signifikan terhadap hasil belajar siswa. Tujuan dari pembelajaran PPKn di SD yaitu untuk menumbuhkan wawasan dan kesadaran bernegara, serta membentuk sikap dan perilaku cinta tanah air yang dilandaskan kebudayaan dan filasafat pancasila.

Berdasarkan PLP yang dilakukan peneliti pada tanggal 04 Agustus 2020 di sekolah pada saat proses pembelajaran banyak sekali ditemukannya siswa yang pasif saat proses pembelajaran, interaksi antar siswa yang kurang saat belajar, serta tidak adanya diskusi kelompok saat belajar padahal belajar kelompok termasuk dalam karakteristik pembelajaran kurikulum 2013, serta siswa tidak bertanggung jawab mengerjakan tugasnya. Sehingga hal tersebut dapat mempengaruhi hasil belajarnya, terutama pada muatan pembelajaran PPKn di kelas IV banyak ditemukan nilai UTS siswa di bawah KKM. KKM PPKn pada kelas IV di SDN 221/II Talang Pamesun adalah 65 .

Tabel 1 Nilai Ujian Tengah Semester PPKn Kelas IV

\begin{tabular}{|c|c|c|c|}
\hline No & Nilai & Jumlah & Persentase \\
\hline 1. & $30-64$ & 9 & $75 \%$ \\
\hline 2. & $65-100$ & 3 & $25 \%$ \\
\hline
\end{tabular}

Sumber : Wali Kelas IV SDN 221/II Talang Pamesun

Berdasarkan data diatas, dapat dilihat bahwa dari 12 orang siswa hanya 3 orang atau $25 \%$ yang mencapai ketuntasan. Siswa yang tidak mencapai ketuntasan 9 orang atau $75 \%$ siswa yang berada di bawah KKM. Adapun KKM yang ditetapkan yaitu 65. Berdasarkan permasalahan yang ditemukan peneliti di sekolah perlu adanya solusi untuk mengatasi permasalahan tersebut yaitu dengan menggunakan model pembelajaran yang inovatif dan menarik serta model yang dapat mengatasi rasa kejenuhan, dan meningkatkan hasil belajar siswa. Model pembelajaran yang tepat bagi guru untuk siswa dalam proses pembelajaran yaitu penelitimemilih model pembelajaran Numbered Head Together (NHT). Berdasarkan uraian diatas, dengan ditemukannya berbagai permasalahan pada proses pembelajaran di sekolah penelititertarik mengambil judul "Pengaruh Model Pembelajaran Numbered Head Together (NHT) Terhadap Hasil Belajar Siswa Muatan Pembelajaran PPKn Kelas IV di SDN 221/II Talang Pamesun". 


\section{METODE PENELITIAN}

Jenis penelitian yang digunakan pada penelitian ini yaitu kuantitatif dengan metode penelitiannya yaitu eksperimen. Penelitian kuantitatif merupakan metode yang berlandaskan pada filsafat positivisme (pengetahuan itu semata-mata berdasarkan pengalaman dan ilmu yang pasti) yang digunakan untuk meneliti pada (Sugiyono, 2017). Desain yang digunakan yaitu pre-experimental designs. Dalam pre-experimental desings peneliti menggunakan bentuk one grup pretest-posttest design. One grup pretes-posttest design menggunakan satu kelas untuk penelitian serta menggunakan pre-test sebelum diberikan perlakuan (treatment) sehingga hasil perlakuan dapat diketahui dengan akurat, karena membandingkan dengan keadaan sebelum diberikan perlakuan. Alasan menggunakan One grup pretest-posttest design karena saat melakukan penelitian menggunakan satu kelas.

Sampel yang digunakan pada penelitian ini adalah seluruh siswa kelas IV di SDN 221/II Talang Pamesun dengan menggunakan teknik sampling jenuh. Sampling jenuh merupakan penelitian yang dilakukan jika jumlah sampel semua anggota populasi relatif kecil kurang dari 30 orang (Sugiyono, 2017). Instrumen yang digunakan pada penelitian ini soal pilihan ganda yang sudah diuji validasi, reliabilitas, daya beda dan tingkat kesukaran. Teknik pengumpulan data penelitian ini diawali dengan pretest, siswa diberikan 20 butir soal pilihan ganda, setelah itu siswa diberikan treatment atau perlakuan dengan menggunakan Model Pembelajaran Numbered Head Together (NHT) pada saat pembelajaran PPKn di kelas IV, terakhir siswa diperikan posttest dengan soal yang sama. Tujuannya untuk melihat apakah ada peningkatan pada siswa sebelum dan sesudah diberikan perlakuan.

Teknik analisis data menggunakan uji normalitas dan uji hipotesis. Uji normalitas bertujuan untuk melihat apakah data yang didapat berdistribusi normal atau tidak. uji normalitas dengan menggunakan uji Shapiro-wilk. Setelah dilakukan uji normalitas, selanjutnya di uji hipotesis dengan menggunkan uji paired sample ttest. Uji hipotesis bertujuan untuk melihat apakah data berpengaruh atau tidak. uji normalitas dan uji hipotesis menggunakan program SPSS 20.

\section{HASIL DAN PEMBAHASAN}

\section{A. Deskripsi Data}

Pada penelitian ini terdapat 12 siswa pada kelas IV di SDN 221/II Talang Pamesun yang telah ditetapkan menjadi sampel penelitian. Sebelum dilakukan treatment (perlakuan) kepada siswa, siswa di berikan soal pretest terlebih dahulu. Selanjutnya siswa diberikan treatment (perlakukan) dengan menggunkan model pembelajaran Numbered Head Together (NHT). Menurut (Kholis, 2017) mengatakan bahwa Numbered Head Together merupakan model pembelajaran dimana siswa diberi nomor kemudian dibuat suatu kelompok kemudian secara acak guru 
memanggil nomor dari siswa. Setelah diberikan perlakuan, terakhir siswa diberikan soal posttest untuk mengetahui hasil belajar siswa. Setelah diperoleh data pretest dan posttest siswa kelas IV SDN 221/II Talang Pamesun, selanjutnya data disajikan menurut nilai tertinggi (Xmaks), nilai terendah (Xmin), dan nilai rata-rata siswa. Adapun data hasil pretest dan posttest dapat disajikan pada tabel dibawah ini:

Tabel 2 Data Hasil Pretest dan Posttest Siswa

\begin{tabular}{|c|c|c|}
\hline Deskripsi Data & Pretest & Posttest \\
\hline Jumlah siswa & 12 & 12 \\
\hline Jumlah nilai & 665 & 920 \\
\hline Rata-rata & 55,41667 & 76,66667 \\
\hline Xmaks & 75 & 95 \\
\hline Xmin & 40 & 65 \\
\hline
\end{tabular}

Berdasarkan analisis pada pretest dan posttest siwa diatas, dapat dijelaskan bahwa nilai rata-rata pretest siswa yaitu 55,41667 dan nilai rata-rata posttest siswa yaitu 76,66667 . Berdasarkan nilai pretest dan posttest tersebut dapat dilihat bahwa nilai rata-rata posttest lebih tinggi dari pada nilai rata-rata pretest. Untuk dapat melihat dengan jelas perbandingannya nilai pretest dan posttest siswa maka peneliti menyajikan dalam bentuk diagram. Berikut ini diagram perbandingan nilai rata-rata pretest dan posttest siswa kelas IV SDN 221/II Talang Pamesun.

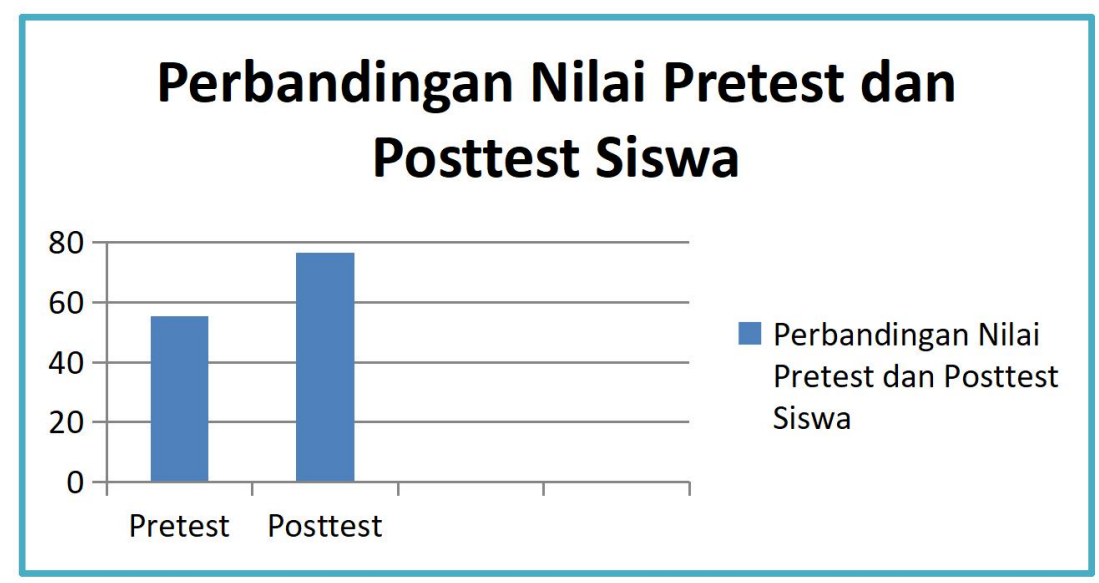

Gambar 1 Perbandingan Nilai Pretest dan Posttest Kelas IV 
Gambar diatas menyajikan perbandingan nilai rata-rata pretest dan posttest siswa kelas IV di SDN 221/II Talang Pamesun. Nilai rata-rata pretest adalah 55,41667 sedangkan nilai rata-rata posttest adalah 76,66667. Maka selisih antara nilai ratarata pretest dan posttest yaitu sebesar 21,25. Dari selisih tersebut dapat dilihat bahwa Perbandingan nilainya meningkat dari nilai rata-rata pretest ke nilai rata-rata posttest. Artinya nilai siswa meningkat setelah diberikan treatment (perlakuan) dengan menggunakan model pembelajaran Numbered Head Together (NHT).

\section{Pengujian Persyaratan Analisis}

Sebelum melakukan uji hipotesis, salah satu hal yang harus dipenuhi agar paramentrik dapat dilakukan dalah penelitian adalah data harus dilakukan uji normalitas. Pengujian data dapat dilakukan untuk mengetahui apakah data yang diperoleh pada hasil penelitian berada pada normal atau tidak. Setelah data berdistribusi normal maka dapat dilakukan uji hipotesis. Uji normalitas dilakukan dengan bantuan SPSS 20 menggunakan tes Shapiro wilk, dengan kriterianya adalah jika signifikansi hasil lebih besar dari 0,05 artinya berdistribusi normal. Sedangkan jika signifikansi hasil lebih kecil dari 0,05 artinya tidak berdistribusi normal. Data yang diuji normalitasnya yaitu pretest dan posttest. Berikut ini tabel uji normalitas data pretest dan posttest kelas IV SDN 221/II Talang Pamesun.

Tabel 3 Hasil Uji Normalitas Pretest dan Posttest

\begin{tabular}{|r|r|r|rr|}
\hline \multicolumn{1}{|c|}{ hasil belajar siswa } & \multicolumn{3}{|c|}{ Shapiro-Wilk } \\
\cline { 3 - 5 } \multicolumn{1}{c|}{} & \multicolumn{1}{|c|}{ Statistic } & Df & \multicolumn{2}{c|}{ Sig. } \\
\multirow{2}{*}{ hasil } & Pretest & .947 & 13 & .550 \\
& Posttest & .913 & 11 & .264 \\
\hline
\end{tabular}

Berdasarkan tabel diatas, dapat dilihat bahwa signifikansi yang diperoleh dari data pretest yaitu $0,550>0,05$ dan signifikansi yang diperoleh dari data posttest yaitu $0,264>0,05$. Artinya data pretest dan posttest siswa kelas IV SDN 221/II Talang Pamesun adalah berdistribusi normal.

\section{Pengujian Hipotesis}

Pengujian hipotesis dilakukan untuk mengetahui apakah hipotesis yang diajukan diterima atau ditolak. Setelah data pretest dan posttest hasil belajar PPKn berdistribusi normal, maka setelah itu dilakukan uji hipotesis dengan menggunakan SPSS 20. Peneliti melakukan uji paired samples t-test. Uji paired samples t-test bertujuan untuk mengetahui apakah ada pengaruh atau tidak terhadap model 
pembelajaran yang digunakan dalam proses pembelajaran pada siswa kelas IV SDN 221/II Talang Pamesun. Berikut ini adalah tabel uji paired samples t-test.

Tabel 4 Hasil Uji Paired Samples T-Test

\begin{tabular}{|c|c|c|c|c|c|c|c|c|c|}
\hline & & & & Paire & Samples T & & & & \\
\hline & & & & Paired I & fferences & & & & \\
\hline & & Mean & $\begin{array}{l}\text { Std. } \\
\text { Deviati } \\
\text { on }\end{array}$ & $\begin{array}{l}\text { Std. } \\
\text { Error } \\
\text { Mean }\end{array}$ & $\begin{array}{r}95 \% \mathrm{C} \\
\text { Interv } \\
\text { Diff }\end{array}$ & $\begin{array}{l}\text { afidence } \\
\text { lof the } \\
\text { rence }\end{array}$ & $\mathrm{T}$ & $\mathrm{df}$ & $\begin{array}{l}\text { sig. } \\
(2- \\
\text { tailed) }\end{array}$ \\
\hline & & & & & Lower & Upper & & & \\
\hline Pair 1 & $\begin{array}{l}\text { Pretest - } \\
\text { Posttest }\end{array}$ & 21.25000 & 3.10791 & .89718 & $\begin{array}{l}- \\
23.22467\end{array}$ & $\begin{array}{l}- \\
19.27533\end{array}$ & -23.685 & 1 & .000 \\
\hline
\end{tabular}

Berdasarkan tabel diatas, dapat diperoleh signifikansi dari uji paired samples t test yaitu $0,000<0,05$ artinya $\mathrm{H}_{0}$ ditolak dan $\mathrm{H}_{\mathrm{a}}$ diterima. Maka dapat disimpulkan bahwa terdapat pengaruh model pembelajaran Numbered head Together (NHT) terhadap hasil belajar siswa muatan pembelajaran PPKn kelas IV di SDN 221/II Talang Pamesun.

\section{B. Pembahasan}

Sebelum dilaksanaannya penelitian di sekolah SDN 221/II Talang Pamesun. Peneliti melakukan uji coba 25 soal pilihan ganda di SDN 212/II Sirih Sekapur Perkembangan. Kemudian dianalisis menggunakan Microsoft excel, hasil dari uji validasi terdapat 5 soal tidak valid dan 20 soal valid. Selanjutnya diuji reliabilitas yang hasilnya soal reliabel. Soal diuji daya beda yang hasilnya 5 soal kategori jelek dan 20 soal kategori baik. Terakhir soal diuji tingkat kesukarannya yang hasil nya 16 soal kategori mudah dan 9 soal kategori sedang.

Pada langkah pertama penelitian yang dilakukan di SDN 221/II Talang Pamesun yaitu pemberian soal pretest kepada siswa. Sebagaimana yang terlihat pada hasil pretest hanya 3 orang siswa yang mencapai kriteria ketuntasan minimal (KKM) 65 , dimana rata-rata kelas hanya 55,41667. Hasil tersebut dapat dinyatakan masih rendah karena belum mencapai KKM. Selain itu, hasil tersebut menunjukkan adanya masalah pada proses pembelajaran sehingga berdampak pada hasil belajar siswa yang belum maksimal. Hasil belajar merupakan kemampuan yang dicapai siswa dari proses belajar yang dapat diketahui dari pencapaian saat melakukan serangkaian tes hasil belajar (Baswan, 2014). Hasil belajar yang di tes adalah kognitif siswa. Selanjutnya peneliti melaksanakan treatment (perlakuan) yang dilaksanakan sebanyak 4 pertemuan. Pelaksanaan treatment (perlakuaan) dilaksanakan sesuai 
dengan RPP. Setelah pemberikan treatment (perlakuan), selanjutnya peneliti memberikan soal posttest kepada siswa. Hasil posttest menunjukkan adanya peningkatan hasil belajar siswa, dimana rata-rata kelas mencapai angka 76,66667. Selain itu, semua siswa mencapai ketuntasan, dimana hasil yang diperoleh sangat baik, nilai tertinggi mencapai angka 95 dan nilai terendah yaitu 65. Usai dilaksanakan penelitian di kelas IV SDN 221/II Talang Pamesun diperoleh data pretest dan posttest. Setelah itu data pretest dan posttest di uji normalitasnya. Hasil uji normalitas data pretest dan posttest memperoleh signifikansi data pretest yaitu $0,550>0,05$ dan signifikansi yang diperoleh dari data posttest yaitu $0,264>0,05$, yang artinya data pretest dan posttest berdistribusi normal. Setelah data berdistribusi normal, selanjutnya dilakukan uji hipotesis dengan menggunakan uji paired samples $\mathrm{t}$ test. Hasil uji paired samples $t$ test yang diperoleh yaitu $0,000<0,05$ artinya $\mathrm{H}_{0}$ ditolak dan $\mathrm{H}_{\mathrm{a}}$ diterima, artinya terdapat pengaruh model pembelajaran Numbered Head Together ( NHT) terhadap hasil belajar siswa muatan pembelajaran PPKn kelas IV di SDN 221/II Talang Pamesun.

\section{KESIMPULAN}

Setelah dilakukan penelitian terhadap pengaruh model pembelajaran Numbered Head Together (NHT) terhadap hasil belajar siswa muatan pembelajaran PPKn kelas IV SDN 221/II Talang Pamesun, selanjutnya dilakukan pengolahan data yaitu uji normalitas dan uji hipotesis menggunakan uji paired samples $t$ test. Hasil uji paired samples $t$ test memperoleh signifikansi yaitu $0,000<0,05$ artinya $\mathrm{H}_{0}$ ditolak dan $\mathrm{H}_{\mathrm{a}}$ diterima. Maka dapat ditarik kesimpulan bahwa terdapat pengaruh model pembelajaran Numbered Head Together (NHT) terhadap hasil belajar siswa muatan pembelajaran PPKn kelas IV di SDN 221/II Talang Pamesun. 


\section{DAFTAR RUJUKAN}

Aris, S. (2014). 68 Model Pembelajaran Inovatif dalam Kurikulum 2013. Yogyakarta: Ar-ruzz media.

Baswan. (2014). Meningkatkan hasil belajar siswa pada mata pelajaran PKn pada materi susunan pemerintahan daerah melalui metode bermain peran dikelas IV SD DDI Siboang. Kreatif Tadulako Online, 3 no.(1), 258-275.

Huda, M. (2017). Model-Model Pengajaran dan Pembelajaran. Pustaka belajar.

Kholis, N. (2017). Penggunaan model pembelajaran numbered head together untuk meningkatkan hasil belajar siswa. Kajian Ilmu Pendidikan, 2(1), 69-88.

Sugiyono. (2017). Metode penelitian kuantitatif, kualitatif, dan R\&D. Bandung: Alfebeta. 